\title{
Effects of Using Limestone as a Filler and Starbit E-55 Asphalt as a Binder on the Performance of AC-WC Mixture
}

\author{
Faizul Chasanah*, and Fajariesta Arta Putra \\ Department of Civil Engineering, Faculty of Civil Engineering and Planning, Islamic University of Indonesia
}

\begin{abstract}
Asphalt concrete can be made through several methods including hot mix using Starbit E-55 asphalt as a binder and limestone as filler. This research aimed to determine the feasibility of the use of limestone as filler in AC-WC mixture and to identify the effects of limestone addition on the Marshall Characteristics, Durability, Indirect Tensile Strength (ITS), and Permeability. The first stage was to test the properties of materials consisting of aggregate, asphalt, and limestone. The second stage was to determine the optimum asphalt content with $0 \%, 25 \%, 50 \%, 75 \%$, and $100 \%$ filler proportions, and the last stage was to conduct the Marshall, Immersion, ITS, and Permeability tests. The results showed that limestone has been in accordance with the performance requirements specified for a filler of AC-WC mixture using Starbit E-55 asphalt as a binder. There was a change in the Marshall characteristics of optimum asphalt content. The durability increased, and the ITS values of AC-WC mixture improved along with the increase in limestone proportion. However, the permeability test indicated that the mixture has a poor drainage feature towards water after variation in filler proportions was performed.
\end{abstract}

\section{Introduction}

One of the essential infrastructures nowadays is transportation infrastructure to increase mobility of the society for economic activities. Constructing new roads or overlays is important to increase the existing economic growth.

Asphalt concrete is generally used as a material for the surface course on flexible pavements. The asphalt often used as a binder in road constructions in Indonesia is penetration asphalt $60 / 70$, but this study used Starbit E-55 asphalt because it has a higher softening point value and durability than Pertamina asphalt with penetration 60/70 (Edison, 2010) [1]. In addition, limestone was used as filler because it is cheaper and easier to find than the stone ash from Clereng.

The aim of this research was to determine the feasibility of the use of limestone as filler in AC-WC mixture and to identify the effects of limestone addition on the Marshall characteristics, durability, Indirect Tensile Strength (ITS), and permeability.

\section{Literature Review}

Andri, et al. (2012) in their research showed that limestone filler significantly influenced mixture quality. The limestone contents used in this study were $0 \%, 25 \%$, $50 \%, 75$, and $100 \%$. It was revealed that the $75 \%$ variation could not fulfil the value of optimum asphalt content. The obtained stability values in optimum asphalt content for limestone variations of $0 \%, 25 \%$, and $50 \%$ were $1114,862 \mathrm{~kg}, 1243,425 \mathrm{~kg}$, and $1167,645 \mathrm{~kg}$, respectively. The Marshall Stability values were $303 \%$, $98,301 \%$, and $99,202 \%$. To conclude, limestone addition as a filler could increase mixture quality [2].

Edison (2010) concluded that the index of residual strength caused by Marshall Immersion for 24 hours from two types of mixture remained over the required minimum value of $75 \%$. From the reading of durability curve in Marshall test, the laston mixture which used asphalt modification with Polymer Starbit E-55 was more durable to water infiltration caused by immersion than Pertamina asphalt with penetration 60/70 [1].

Kans (2014) concluded that the AC-WC mixture which used Starbit asphalt E-55 had better characteristics with a stability value of $1,718 \mathrm{~kg}$ in optimum asphalt content of $5.7 \%$, and the mixture that used Pertamina asphalt pen $60 / 70$ reached optimum asphalt content in $6.4 \%$ with a stability value of $1,642.7 \mathrm{~kg}$. Asphalt content of Starbit E-55 in AC-WC mixture was 5.6\%. Based on the test results for immersion treatment with a variation of $1,3,5,7$, and 14 days, the durability of the AC-WC mixture that used asphalt Starbit E-55 was better, but during the process it required $15.38 \%$ more energy [3].

Subarkah and Romadhona (2015) in their research found that bitumen Starbit E-55 could be used as an

\footnotetext{
"Corresponding author: 145110101@uii.ac.id
} 
alternative binder for asphaltic concrete. The optimum bitumen content of bitumen Starbit E-55 in AC-WC was $5.75 \%$ for dense graded and $6.2 \%$ for gap graded. The mixture with bitumen Starbit E-55 was weaker than that of bitumen penetration 60/70 for both dense and gap graded. The immersion test result indicated that the index of retained strength of specimen using bitumen Starbit E-55 was more sensitive than that of the specimen using bitumen Pen 60/70. Meanwhile, in terms of indirect tensile strength, the specimen using bitumen penetration $60 / 70$ was more sensitive than that of the specimen using Starbit E-55 [4].

Ogundipe (2016) in his research indicated that the replacement of the mineral filler with lime improves the stability of the mixtures, while there was slight increase in the flow of the mixture with hydrated lime. The slight increase in stability and flow values may be attributed to the complete replacement of the mineral filler with lime and the high lime content used in the study. More studies are being carried out to evaluate the Marshall properties for mixture with the mineral filler partially replaced with lime and for varying proportions of the lime content in the asphalt mixture [5].

\section{Methodology}

The research used the experimental method by conducting an experiment to obtain and analyze data. The data was then processed to be compared with the standard specifications. The terms and procedures referred to the Indonesian National Standard and Directorate General of Highways (2010) [6]. The sampling method in this research was a non-probability sampling, that is, the samples were not selected randomly but determined based on the research objectives. In this study, the researcher took a coarse aggregate and fine aggregate sampling from Clereng, which was available in the Highway Laboratory of Civil Engineering Department of Islamic University of Indonesia. Meanwhile, the asphalt Starbit E-55 was obtained from PT. Bintang Djaja, Cilacap, and the limestone was bought from a building supply store in Yogyakarta.

Analysis of the test data was conducted as follows:

1. Analysis of Marshall characteristics

This analysis included stability, flow, Marshall Quotient, Void in the Total Mix, Void Filler with Asphalt, Void in Mineral Aggregate, and density value.

2. Analysis of Immersion Test

This analysis was conducted to determine the characteristic changes in the mixture due to the influence of water, temperature, and weather. This test had the same principle as the standard Marshall testing but with different immersion time in waterbath.

3. Analysis of Indirect Tensile Strength Test This analysis was conducted to determine the value of the tensile strength of the concrete asphalt.

4. Analysis of Permeability
This analysis was conducted to identify the surface course ability to hold water seepage into the pavement.

This research flow chart is presented in Figure 1.

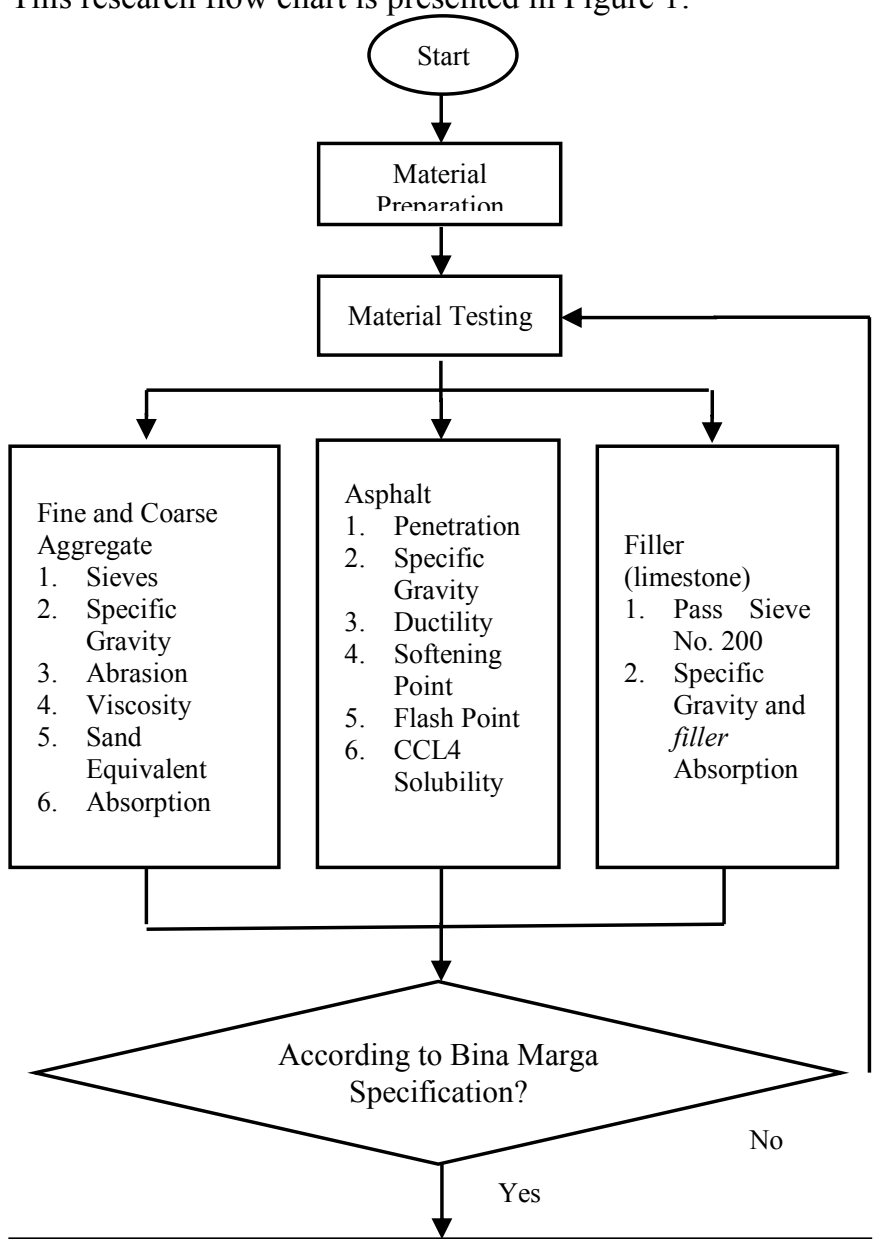

Making 75 samples using limestone as filler with content variation of $0 \%, 25 \%, 50 \%, 75 \%$, and $100 \%$ to determine optimum asphalt content

Making 60 samples using lime stone as filler with content variation of $0 \%, 25 \%, 50 \%, 75 \%$, and $100 \%$ of optimum asphalt content for Marshall, Immersion, Indirect Tensile Strength, and Permeability tests

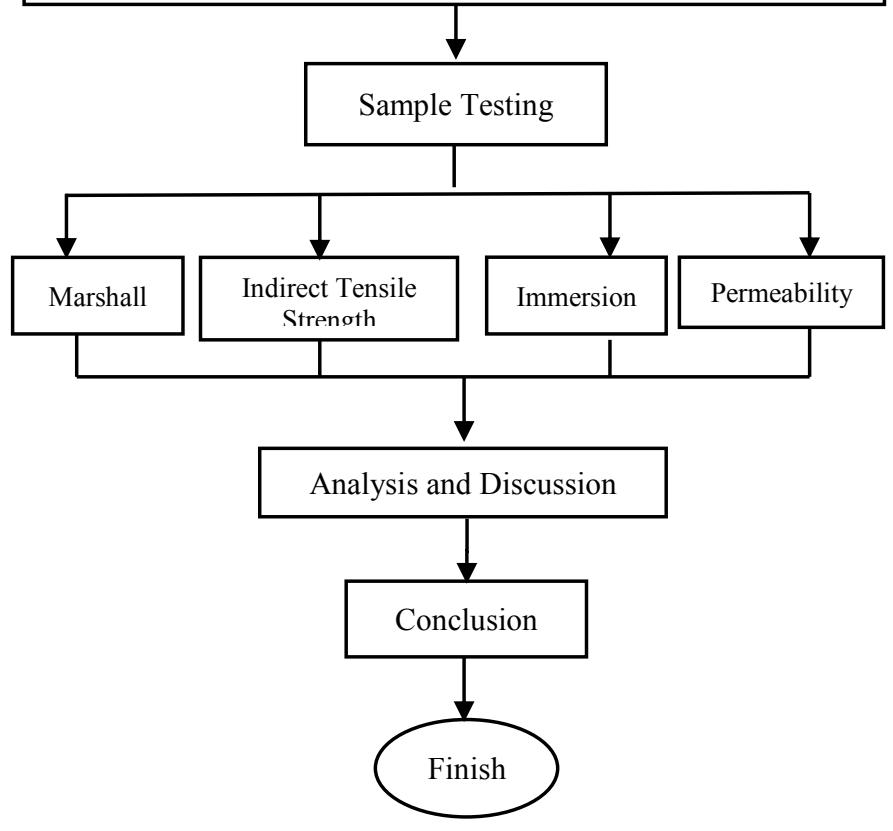


Fig. 1. Research Flow Chart

\section{Results and Discussion}

The test was conducted at the Highway Laboratory of Civil Engineering of Islamic University of Indonesia using the standard specifications from the Directorate General of Highways (2010) [6].

\subsection{Test of material characteristics}

This test was intended to identify the physical properties and characteristics of asphalt, fine aggregate, coarse aggregate, and filler. Test results are presented in Table 1, Table 2, Table 3, Table 4, and Table 5 below.

Table 1. Test results of Starbit E-55 asphalt

\begin{tabular}{|c|lc|c|c|}
\hline No. & \multicolumn{2}{|c|}{ Type of Test } & $\begin{array}{c}\text { Terms } \\
\text { Value }\end{array}$ & Result \\
\hline 1 & Specific gravity & $\geq 1.0$ & 1.0 \\
\hline 2 & Penetration & $(0.1 \mathrm{~mm})$ & Min. 40 & 52.5 \\
\hline 3 & Ductility & $(\mathrm{cm})$ & $\geq 100$ & 164 \\
\hline 4 & Flash Point & $\left({ }^{\circ} \mathrm{C}\right)$ & $\geq 232$ & 330 \\
\hline 5 & $\begin{array}{l}\text { Solubility of } \\
\text { TCE }\end{array}$ & $(\%)$ & $\geq 99$ & 99.25 \\
\hline 6 & Soft Spot & $\left({ }^{\circ} \mathrm{C}\right)$ & $\geq 48$ & 55.5 \\
\hline 7 & $\begin{array}{l}\text { Asphalt } \\
\text { Attachment }\end{array}$ & $(\%)$ & $\geq 90$ & 98 \\
\hline
\end{tabular}

Table 2. Test results of Clereng coarse aggregate

\begin{tabular}{|c|lc|c|c|}
\hline No. & \multicolumn{1}{|c|}{ Type of Test } & $\begin{array}{c}\text { Terms } \\
\text { Value }\end{array}$ & Result \\
\hline 1 & Specific gravity & $\geq 2.5$ & 2.627 \\
\hline 2 & $\begin{array}{l}\text { Aggregate absorption to } \\
\text { water }\end{array}$ & $<3$ & 2.737 \\
\hline 3 & $\begin{array}{l}\text { Aggregate attachment to } \\
\text { asphalt }\end{array}$ & $\mathbf{( \% )}$ & $>95$ & 98.5 \\
\hline 4 & $\begin{array}{l}\text { The wear with Los } \\
\text { Angeles machine }\end{array}$ & $\mathbf{( \% )}$ & $<40$ & 19.46 \\
\hline
\end{tabular}

Table 3. Test results of Clereng fine aggregate

\begin{tabular}{|c|lc|c|c|}
\hline No. & \multicolumn{1}{|c|}{ Type of Test } & $\begin{array}{c}\text { Terms } \\
\text { Value }\end{array}$ & Result \\
\hline 1 & Specific gravity & $\geq 2.5$ & 2.795 \\
\hline 2 & $\begin{array}{l}\text { Aggregate absorption to } \\
\text { water }\end{array}$ & $<3$ & 1.730 \\
\hline 4 & Sand Equivalent $\quad(\%)$ & $>50$ & 72.72 \\
\hline
\end{tabular}

Table 4. Test results of Clereng stone ash filler

\begin{tabular}{|c|l|c|c|}
\hline No. & \multicolumn{1}{|c|}{ Type of Test } & Terms Value & Result \\
\hline 1 & Specific gravity & $\geq 2.5$ & 2.638 \\
\hline 2 & Water absorption & $<3$ & 1.07 \\
\hline
\end{tabular}

Table 5. Test results of limestone filler

\begin{tabular}{|c|l|c|c|}
\hline No. & \multicolumn{1}{|c|}{ Type of Test } & Terms Value & Result \\
\hline 1 & Specific gravity & $\geq 2.5$ & 2.513 \\
\hline 2 & Water absorption & $<3$ & 1.14 \\
\hline
\end{tabular}

The test results indicated that the physical properties and characteristics of asphalt, fine aggregate, coarse aggregate, and filler have been in accordance with the standard specifications.

\subsection{Marshall test for optimum asphalt content}

Marshall test is proposed to determine the stability and flow of asphalt mixture. From the figure of the relationship between asphalt content and Marshall parameters, the optimum asphalt content will be obtained.

1. Stability

Stability is the ability of pavement to resist deformation due to traffic load without any changes in shape, such as waves and grooves.

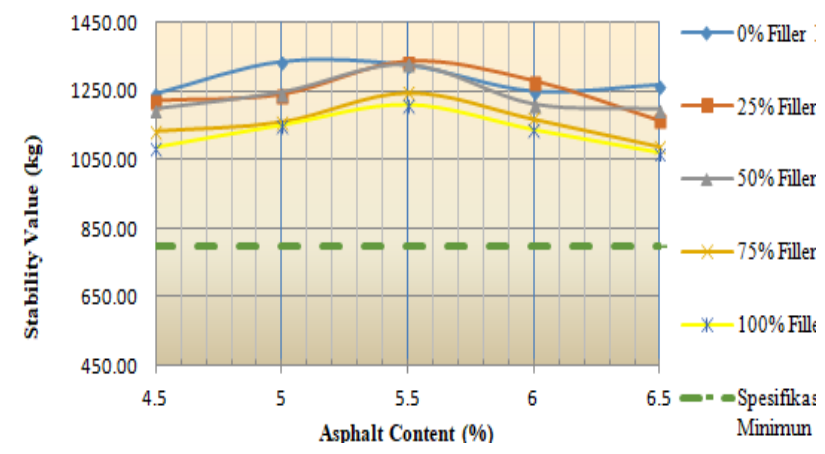

Fig. 2. Stability value of optimum asphalt content

Based on the graph in Figure 2, the stability value at the same bitumen content tends to decrease with the addition of limestone filler content to the mixture. This is because the specific gravity of the Clereng stone ash filler type is slightly larger than that of the limestone filler. At the same weight, the mixture using limestone filler has a likely greater volume. It causes the aggregate surface area in the mixture to become larger, and the consequence is the need for asphalt to bind the larger aggregate grains. This has resulted in the same amount of asphalt, and the covered aggregate surface area is also smaller.

2. Flow

Flow is a change in the shape of a mixture which occurs due to a load to the limit of collapse expressed in units of length (mm). The flow value is shown in Figure 3. 


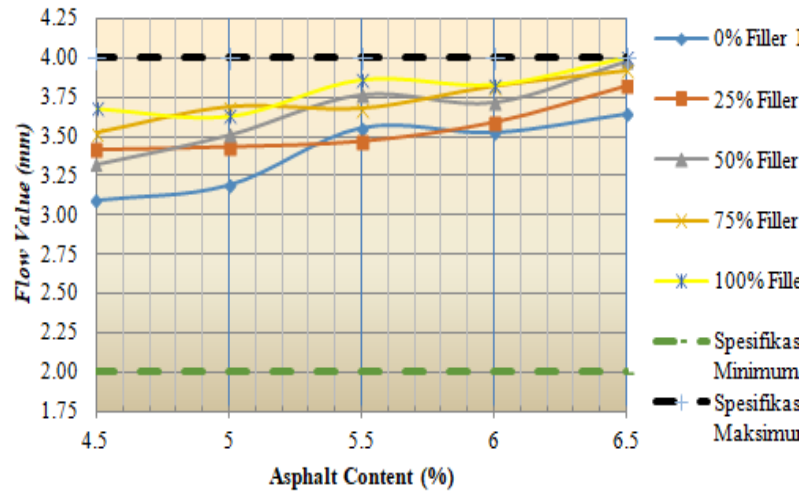

Fig. 3. Flow value of optimum asphalt content

Based on the graph in Figure 3, by increasing the proportion of limestone filler content, the flow value will improve because limestone is more easily mixed with Starbit E-55 asphalt to form lower mastics, making the mixture more plastic and accepting load means experiencing greater plastic deformation.

3. MQ (Marshall Quotient)

The Marshall Quotient value is the quotient between the stability value and the flow value commonly used as an approach to the stiffness and flexibility of the mixture. The MQ value is shown in Figure 4.

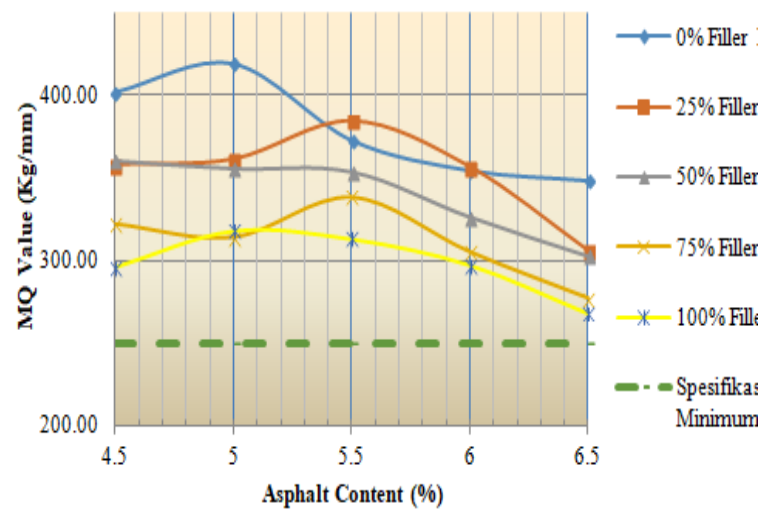

Fig. 4. MQ value of optimum asphalt content

Figure 4 shows that the Marshall Quotient value tends to decrease with the addition of bitumen content. This is because the Starbit E-55 asphalt gradation of ACWC mixture increases and is influenced by the stability value. In this mixture, the use of limestone as filler produces decreasing Marshall Quotient values. This is due to the mixture stability with limestone filler that has a lower value and a higher flow, indicating that the mixture using limestone filler tends to be plastic when receiving load.

4. VITM (Void in the Total Mixture)

VITM is a value indicating the number of voids in the mixture, expressed as a percentage of the total volume of the aggregate and asphalt mixtures. The VITM value is shown in Figure 5.

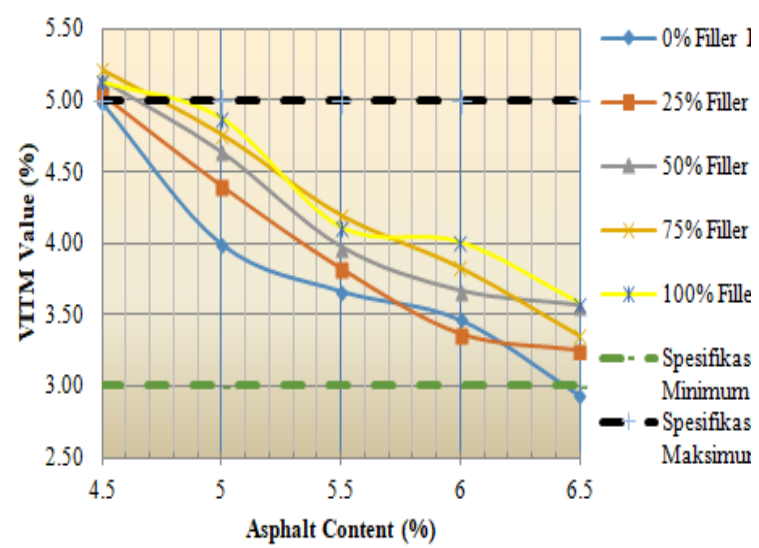

Fig. 5. VITM value of optimum asphalt content

The graph in Figure 5 shows that if the asphalt content increases, the value of VITM decreases since the voids filled with asphalt are greater, making the mixture increasingly compacting. In the mixture with the same asphalt content, the mixture using the limestone filler content has a VITM value which tends to be larger. This is because the absorption of limestone filler is likely to be greater than that of the Clereng stone ash filler, thus causing more asphalt to be absorbed first in the limestone filler resulting in the increase in the cavity formed in the mixture and therefore increasing the VITM value.

5. VFWA (Void Filled with Asphalt)

VFWA is a value indicating the percentage of voids existing in the mixture filled with asphalt. The VFWA value is shown in Figure 6.

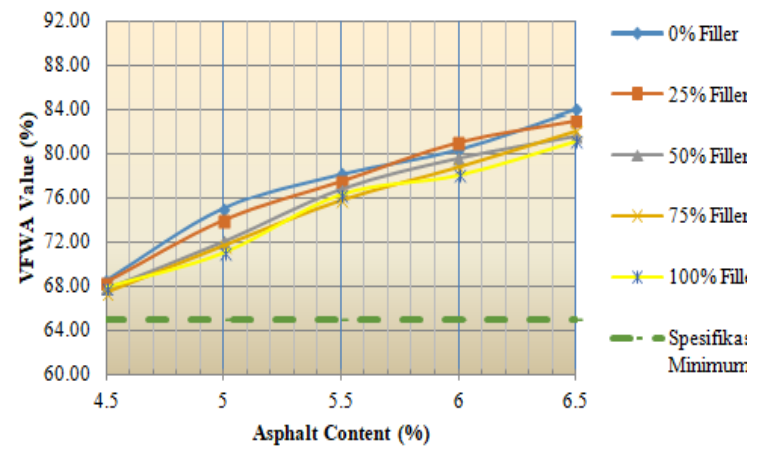

Fig. 6. VFWA value of optimum asphalt content

The graph in Figure 6 indicates that, along with the increase in asphalt content, VFWA value also increases because there is more content of Starbit E-55 asphalt in AC-WC mixture that can fill the voids in the mixture. The absorption of limestone filler against the larger volume of water can also cause the VFWA value to become smaller. Filler absorption of a large volume of water will cause the asphalt absorbed by the filler to be large as well. This will result in less residual asphalt covering the void in the mixture and a greater percentage of cavities in the asphalt filled mixture becoming smaller.

6. VMA (Void in Mineral Aggregate)

VMA is the percentage of the number of voids between the aggregate grains in the mixture, or it can be 
expressed as the percentage of voids which are available for asphalt and air. The VMA value is shown in Figure 7.

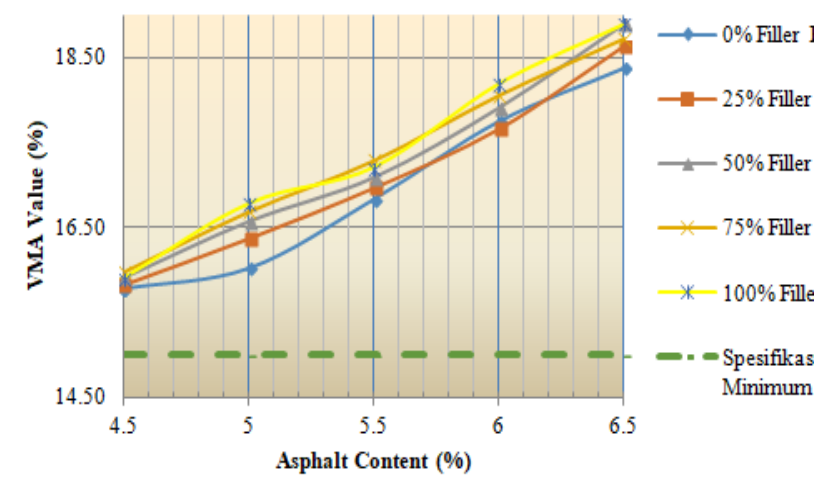

Fig. 7. VMA value of optimum asphalt content

Based on the graph in Figure 7, it can be seen that the value of VMA increases along with the increasing bitumen content. As more voids are filled with asphalt, the mixture becomes more impermeable to water and air. In the mixture with the same bitumen content, the use of more limestone filler produces a higher VMA value since the absorption of larger limestone filler results in faster absorption of asphalt and increasing cavity in the mixture.

7. Density

Density is the density of a mixture measured per unit of volume. The density value is shown in Figure 8.

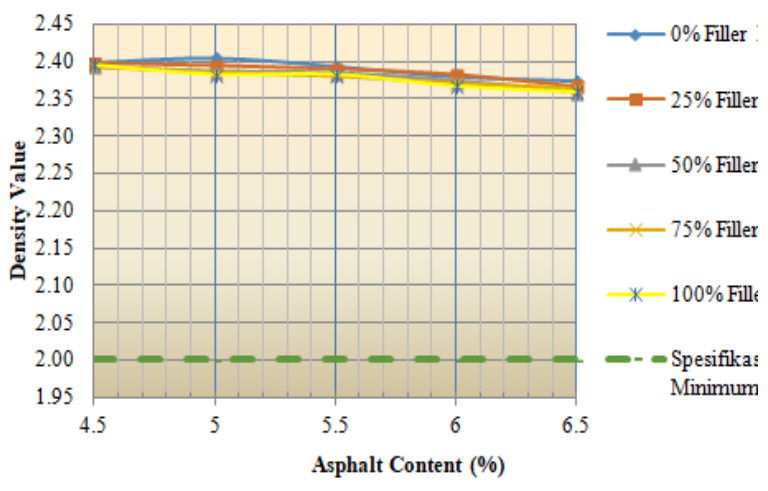

Fig. 8. Density value of optimum asphalt content

Based on Figure 8, the larger content of limestone filler in the mixture can decrease the density value. This is because the limestone filler, which has a higher absorption value than the Clereng stone ash filler, will slightly absorb the Starbit E-55 asphalt which results in a larger cavity volume, making the density of the mixture decreased.

\subsection{Value of optimum asphalt content}

The analysis of Marshall test data results in the values of stability, flow, VMA (Void in Mineral Aggregate), VFWA (Void Filled with Asphalt), VITM (Void in the Total Mixture), MQ (Marshal Quotient), and Density. The results of the analysis of each Marshall characteristic and bitumen content are used to determine the optimum bitumen content presented in Table 6 .

Table 6. Optimum asphalt content recapitulation

\begin{tabular}{|c|c|}
\hline Lime Content (\%) & Optimum Asphalt Content \\
\hline 0 & 5.48 \\
\hline 25 & 5.53 \\
\hline 50 & 5.57 \\
\hline 75 & 5.63 \\
\hline 100 & 5.65 \\
\hline
\end{tabular}

\subsection{Tests after optimum asphalt content}

1. Stability

The result of stability data analysis with increasing filler content is shown in Figure 9.

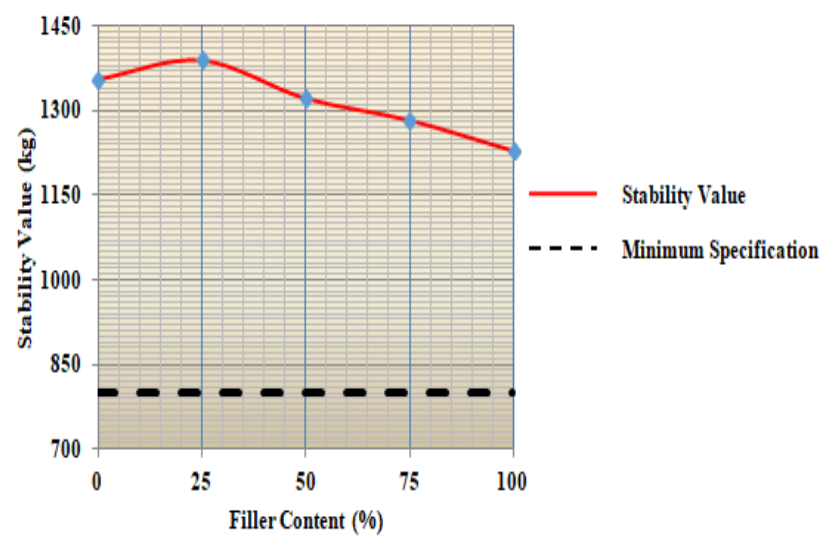

Fig. 9. Graph of relation between lime stone content and stability value

The graph in Figure 9 shows that the stability value increases with the maximum condition at $25 \%$ limestone filler content, and then it tends to decrease as the proportion of limestone filler increases. This is because limestone filler content has a slightly lower specific gravity value than the Clereng stone ash filler; therefore, with equal weight proportions, the mixture with limestone filler has more grain volume. As the lime stone filler proportions increase, the greater grain extent should be covered by the asphalt. However, there is an optimum mixture with $25 \%$ limestone filler mixture, in which $25 \%$ of the limestone filler is capable of filling the existing aggregate cavity well. Therefore, the amount of asphalt covering and binding aggregate grains increases in $25 \%$ limestone filler then decreases, reducing the stability value.

2. Flow

The result of flow data analysis with increasing filler content is shown in Figure 10. 


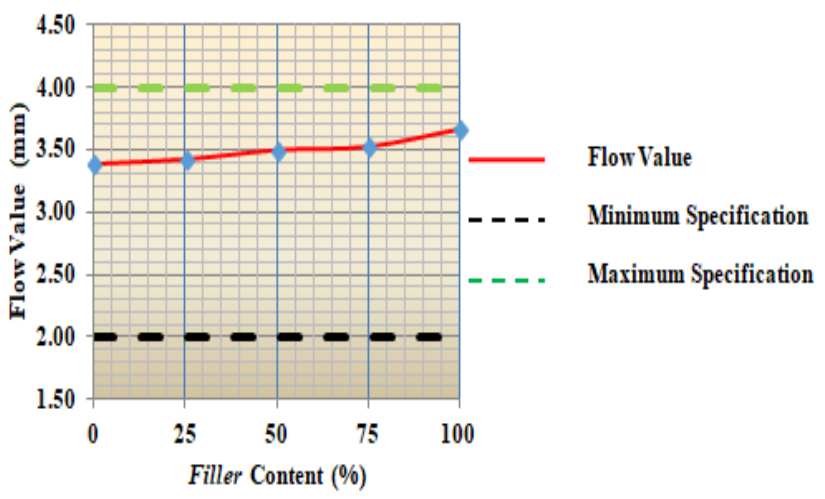

Fig. 10. Graph of relation between lime stone content and flow value

Figure 10 indicates that the flow value increases with the increase in the proportion of limestone filler content in the mixture because limestone is easier to mix with Starbit E-55 asphalt to form less mastic. Consequently, the mixture becomes more plastic and will experience greater plastic deformation when load is given.

\section{Marshall Quotient}

The result of MQ data analysis with increasing filler content is shown in Figure 11.

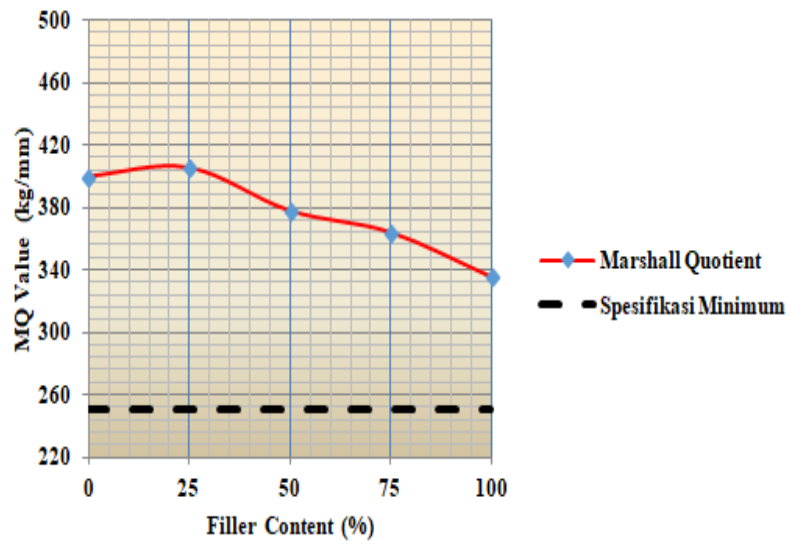

Fig. 11. Graph of relation between lime stone content and $M Q$ value

Based on Figure 11, it can be seen that the AC-WC mixture with limestone filler content has a higher Marshall Quotient value in the limestone filler proportion of $25 \%$, and then the rest is decreasing. This is because the stability value of the mixture with limestone filler has a higher value at $25 \%$ filler mixture and higher flow value, but then lower stability value is obtained due to the addition of limestone filler and higher flow value. This indicates that the mixture using limestone filler tends to become plastic when receiving load.

4. VITM (Void in the Total Mixture)

The result of VITM data analysis with increasing filler content is shown in Figure 12.

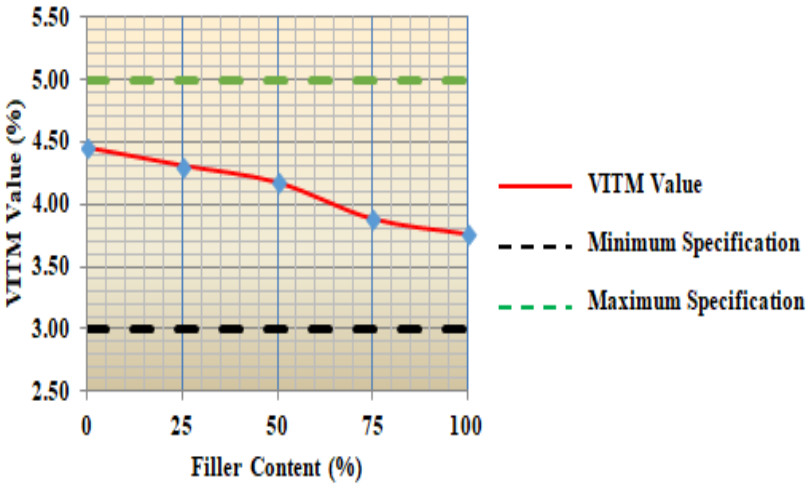

Fig. 12. Graph of relation between lime stone content and VITM value

Based on the graph in Figure 12, the greater percentage of limestone filler as replacement for Clereng stone ash filler in Starbit E-55 asphalt mixture of ACWC gradation will result in continuously decreasing VITM value. Asphalt mixture of Starbit E-55 gradation AC-WC using limestone filler has a VITM value that tends to be lower than that of the asphalt mixture of Starbit E-55 gradation AC-WC without limestone filler. This decrease in VITM shows that the cavities in the mixture become smaller, making the mixture denser due to the slightly smaller limestone filler type. As a result, with the same proportion of weight, limestone filler has a greater volume than Clereng stone ash filler, resulting in smaller air cavity in the mixture and denser texture of the mixture.

5. VFWA (Void Filled With Asphalt)

The result of VFWA data analysis with increasing filler content is shown in Figure 13.

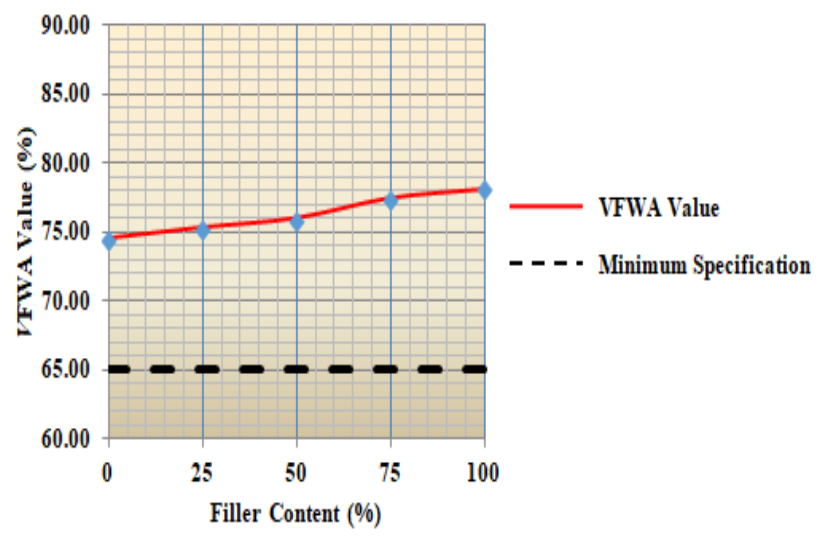

Fig. 13. Graph of relation between lime stone content and VFWA value

Based on the graph in Figure 13, when limestone filler content increases, the VFWA value also increases as the density of limestone filler is slightly smaller than that of the Clereng stone ash filler. Therefore, the volume of limestone filler is also greater, resulting in voids in the mixture filled by limestone filler and tighter mixture. 
6. VMA (Void in Mineral Aggregate)

The result of VMA data analysis with increasing filler content is shown in Figure 14.

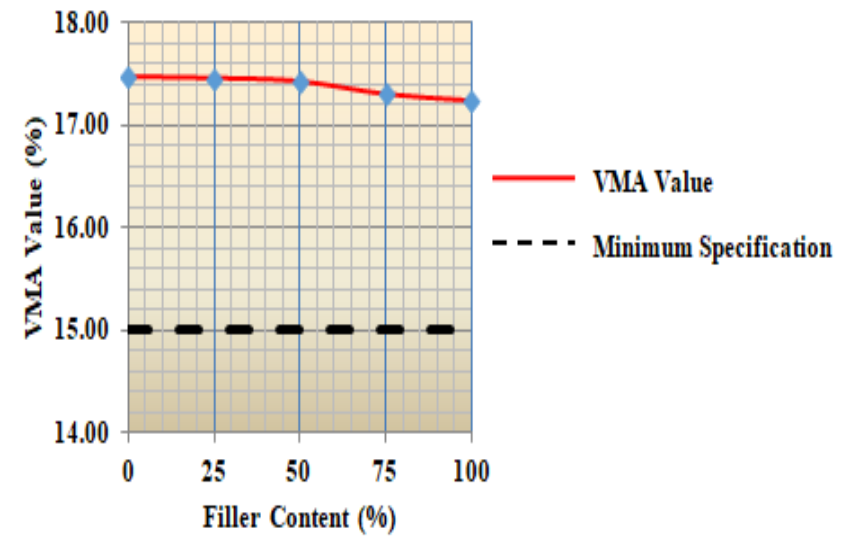

Fig. 14. Graph of relation between lime stone content and VMA value

The graph in Figure 14 shows that greater percentage of limestone filler in the asphalt mixture of Starbit E-55 gradation $\mathrm{AC}-\mathrm{WC}$ reduces the VMA value because the limestone filler has a lower specific gravity value compared to the Clereng stone ash filler; hence, the greater the limestone content, the more the filler volume that fills the cavity, and the mixture will then be relatively the same or slightly more dense with shorter distance between the aggregate minerals.

\section{Density}

The result of density data analysis with increasing filler content is shown in Figure 15.

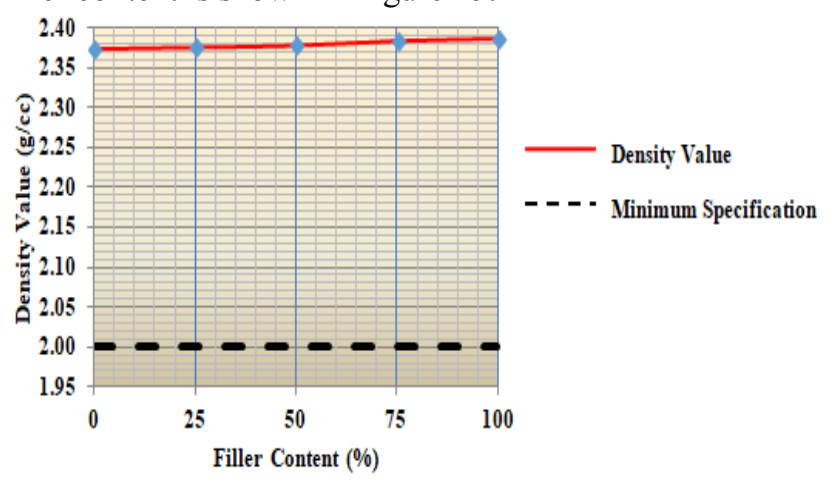

Fig. 15. Graph of relation between lime stone content and Density value

The graph in Figure 15 indicates that the density value has increased along with the increase in the proportion of limestone filler content in the Starbit E-55 asphalt gradient AC-WC mixture. This increase is due to the specific gravity of the limestone filler which is lower than that of the Clereng stone ash filler. Smaller density has a larger volume, and along with the addition of limestone filler content, the density value increases as the cavities in the mixture become smaller and mixed closer.

\subsection{Immersion test}

In this test, the values of immersion stability and the Index of Retained Strength (IRS) are obtained.

1. Immersion Stability

The result of immersion stability data analysis with increasing filler content is shown in Figure 16.

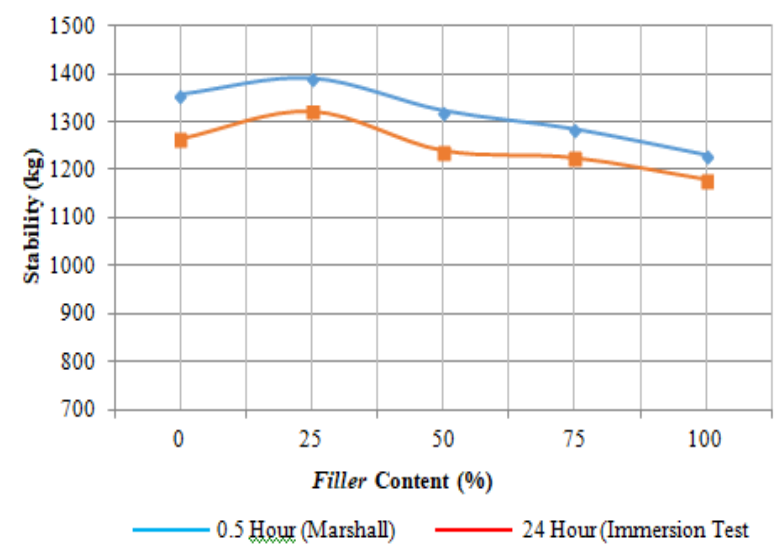

Fig. 16. Graph of relation between lime stone filler content and immersion stability in Immersion Test

Based on the graph in Figure 16, it can be seen that the stability of the 24-hour immersion is lower than the stability of the immersion of 0.5 hour. This is because the immersion process that reaches 24 hours causes water to enter the pores of the mixture thereby reducing the adhesion bond between asphalt and aggregate.

2. Index of Retained Strength (IRS)

Index of retained strength is the comparison of mixed immersion stability value which aims to identify strength and stiffness. Soaking for this study is immersion for 24 hours at $60^{\circ} \mathrm{C}$ to immersion for 0.5 hour at $60^{\circ} \mathrm{C}$. The result of IRS analysis with increasing filler content is shown in Figure 17.

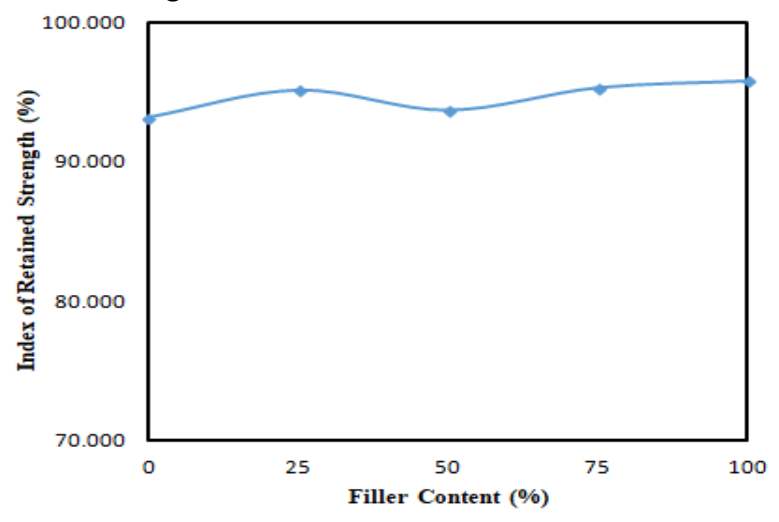

Fig. 17. Index of Retained Strength

Figure 17 shows that along with the larger limestone filler into the AC-WC mixture, the value index of retained strength increases. An increase in the index of retained strength indicates that the mixed resistance due to the influence of water, temperature and weather tends to increase. This is due to the cavities in the smaller ACWC mixture with the addition of limestone filler that can be seen from the higher VFWA values. The IRS value is shown in Table 7. 
Table 7. IRS value

\begin{tabular}{|c|c|c|c|c|}
\hline \multirow{2}{*}{$\begin{array}{c}\text { Filler } \\
\text { Content }\end{array}$} & \multicolumn{2}{|c|}{$\begin{array}{c}\text { Immersion } \\
\text { Time }\end{array}$} & \multirow{2}{*}{$\begin{array}{c}\text { Index of } \\
\text { Retained } \\
\text { Strength } \\
\mathbf{( \% )}\end{array}$} & \multirow{2}{*}{ Annotation } \\
\cline { 2 - 3 } & $\begin{array}{c}\mathbf{0 . 5} \\
\text { Hour }\end{array}$ & $\begin{array}{c}\mathbf{2 4} \\
\text { Hours }\end{array}$ & \\
\hline 0 & 1357 & 1264 & 93.172 & Fulfilled \\
\hline 25 & 1390 & 1323 & 95.130 & Fulfilled \\
\hline 50 & 1323 & 1240 & 93.686 & Fulfilled \\
\hline 75 & 1285 & 1224 & 95.302 & Fulfilled \\
\hline 100 & 1231 & 1179 & 95.780 & Fulfilled \\
\hline
\end{tabular}

\subsection{Indirect tensile strength test}

The result of indirect tensile strength analysis with increasing filler content is shown in Figure 18.

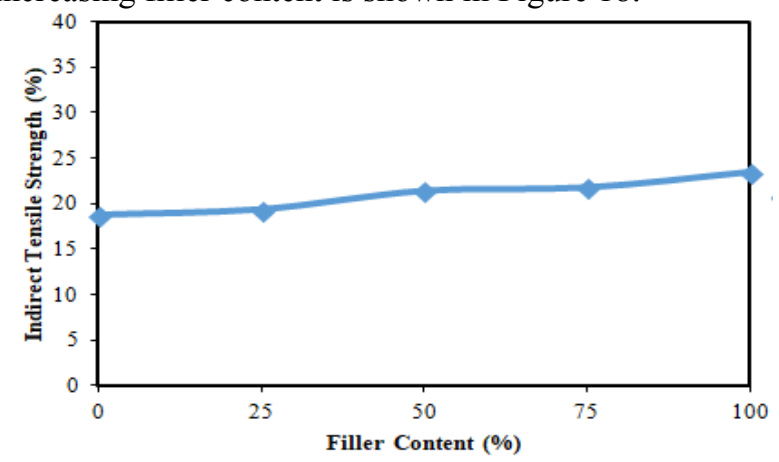

Fig. 18. Indirect Tensile Strength value

Based on Figure 18, it can be seen that the substitution of limestone filler into the Starbit E-55 asphalt gradient mixture of $\mathrm{AC}-\mathrm{WC}$ increases the Indirect Tensile Strength value because the greater the proportion of mixed limestone filler, the more dense the mixture is. Therefore, the aggregate spacing will be smaller and the interlocking effect between the aggregates is greater, resulting in higher resistance to tensile strength.

\subsection{Permeability test}

The result of permeability analysis with increasing filler content is shown in Figure 19.

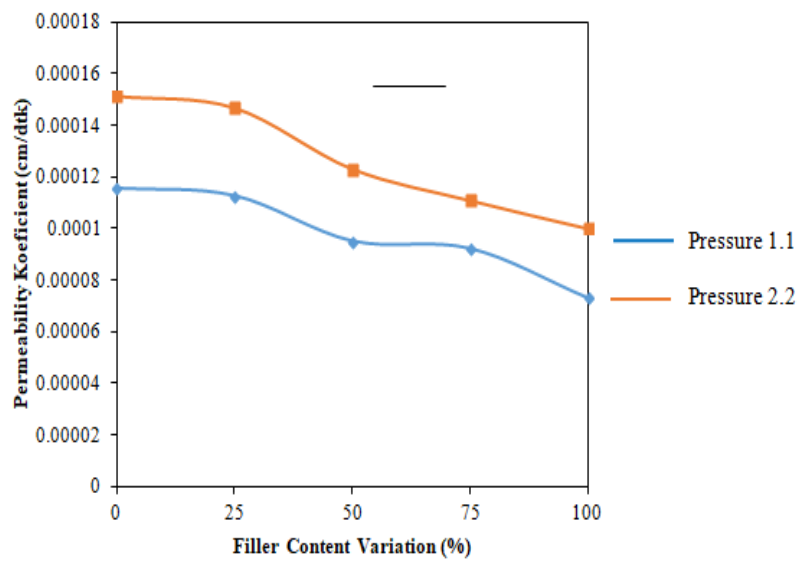

Fig. 19. Permeability value
From Figure 19, the greater limestone filler into the mixture leads to the smaller value of permeability coefficient. In the permeability testing of the mixture using limestone filler, the mixture has poor water drainage properties at either $1 \mathrm{~kg} / \mathrm{cm} 2$ pressure or at a pressure of $2 \mathrm{~kg} / \mathrm{cm} 2$.

In the Starbit E-55 asphalt mixture of AC-WC gradation using limestone filler as a substitution, the VFWA value is greater while VITM and VMA values are smaller, resulting in smaller permeability coefficient value due to the pore of the mixture. The limestone filler is almost completely covered by asphalt and limestone filler has higher absorption. The aggregates in the mixture are almost completely enveloped by the bitumen; hence, the permeability coefficient value decreases or the mixture becomes more impermeable.

\section{Conclusions and recommendations}

Based on the results and discussion, it is concluded that

1. The AC-WC mixture with limestone as the replacement filler undergoes a change in the Marshall characteristics. This can be seen from the increased stability value, at $25 \%$ limestone filler, that decreases along with the addition of filler; also, the flow value increases, MQ value increases in $25 \%$ limestone filler then decreases with the addition of filler, VITM decreases, density increases, VFWA increases, and VMA declines.

2. The AC-WC mixture durability increases along with the addition of limestone filler. This shows that the mixed resistance due to the influence of water, temperature, and weather tends to increase.

3. The Indirect Tensile Strength of AC-WC mixture improves as the proportion of limestone filler increases. This shows that the mixture has better ability to hold the tensile strength so that it tends to be less susceptible to cracking.

4. The permeability test indicates that the mixture has poor drainage properties to water after the limestone filler mixing is done. The permeability value of the Starbit E-55 asphalt gradient mixture of AC-WC with limestone as filler causes the fading.

For future research, it is recommended that the use of limestone as filler substitution in other pavement mixtures or other types of asphalt production is investigated.

\section{References}

1. B. Edison, Jurnal Aptek, 2, 60-71, (2010)

2. Andri, A. Setiawan, N. Pradani, JRMT, II, 87-104 (2012)

3. D. Kans, Thesis, (ETD, Gadjah Mada University, 2014)

4. Subarkah, W. Romadhona, Jurnal Teknisia, XX, 7884, (2015) 
5. O. M. Ogundipe, ScienceDirect, TRP, 14, 685-693 (2016)

6. Directorate General of Highways, Ministry of Public Works, Spesifikasi Umum Revisi 3, (2010) 